\title{
Grazoprevir/elbasvir in peginterferon alfa plus ribavirin experienced patients with chronic genotype I HCV/HIV co-infection: a non-randomized, open-label clinical trial
}

This article was published in the following Dove Press journal: Infection and Drug Resistance

\author{
Yi-Chun Lin ${ }^{1} * *$ \\ Shih-Wei $\mathrm{Li}^{2, *}$ \\ Shin-Yen $\mathrm{Ku}^{3}$ \\ Hui-Ting Hsieh ${ }^{3}$ \\ Mei-Hui Lin ${ }^{3}$ \\ Shu-Yin Chang ${ }^{3}$ \\ Wei-Wei $\mathrm{Wu}^{3}$ \\ $\mathrm{Na}$-Lee $\mathrm{Sun}^{3}$ \\ Shu-Hsing Cheng ${ }^{1,4}$ \\ Chien-Yu Cheng ${ }^{1,5}$ \\ 'Department of Internal Medicine, \\ Division of Infectious Diseases, Taoyuan \\ General Hospital, Ministry of Health and \\ Welfare, Taoyuan City, Taiwan; ${ }^{2}$ Division \\ of Gastroenterology, Department of \\ Internal Medicine, Taoyuan General \\ Hospital, Ministry of Health and Welfare, \\ Taoyuan City, Taiwan; ${ }^{3}$ Comprehensive \\ HIV Care Center, Taoyuan General \\ Hospital, Ministry of Health and Welfare, \\ Taoyuan City, Taiwan; ${ }^{4}$ School of Public \\ Health, Taipei Medical University, Taipei, \\ Taiwan; ${ }^{5}$ School of Public Health, \\ National Yang-Ming University, Taipei, \\ Taiwan
}

*These authors contributed equally to this work

Correspondence: Chien-Yu Cheng Department of Internal Medicine, Division of Infectious Diseases, Taoyuan General Hospital, Ministry of Health and Welfare, No. I492, Jhongshan Rd.,

Taoyuan District, Taoyuan City, Taiwan 33004, Taiwan

Tel +8863369 9721

Fax +886 33789127

Email s841060@yahoo.com
Background and aims: We aimed to evaluate the efficacy and tolerability of grazoprevir/ elbasvir in patients with chronic genotype 1 hepatitis $\mathrm{C}$ virus (HCV) and HIV co-infection who experienced peginterferon alfa plus ribavirin (PegIFN/RBV) (clinicaltrials.gov NCT03098121).

Methods: This non-randomized, open-label trial study was conducted in Taoyuan General Hospital. HIV-infected patients were screened for HCV antibody since June 1, 2012, and $\mathrm{HCV}$ and HIV co-infected patients were tested for HCV RNA. The subjects who experienced PegIFN/RBV were enrolled in the study, and of whom with chronic genotype 1a or $1 \mathrm{~b}$ received grazoprevir $100 \mathrm{mg}$ and elbasvir $50 \mathrm{mg}$ in a fixed-dose combination tablet once daily with or without ribavirin for 12 to 16 weeks.

Results: Of 2,419 HIV-infected patients, 40 patients with chronic genotype $1 \mathrm{HCV}$ and HIV co-infection who failed PegIFN/RBV treatment were enrolled. Sixteen patients had genotype 1a and 24 patients had genotype $1 \mathrm{~b}$, with or without cirrhosis. The median age was 42 (41-47) years, and 5 patients (12.5\%) were diagnosed with liver cirrhosis (child Pugh score A). The median CD4 count was 504 cells/ $\mu \mathrm{L}$ (321-689). All patients (100\%) had HIV viral load $<200$ copies/mL, and HCV viral load was $6.3 \log _{10} \mathrm{IU} / \mathrm{mL}$ (3.98-7.12). At the end of treatment, all patients $(100 \%, 40 / 40)$ had undetectable HCV viral load, and 95.0\% (38/40) of patients achieved sustained virologic response at 12 weeks.

Conclusion: Grazoprevir/elbasvir was effective in genotype 1 patients co-infected with HIV with or without cirrhosis. This finding is consistent with that of previous trials of this regimen in monoinfected population.

Keywords: hepatitis $\mathrm{C}$, grazoprevir and elbasvir, PEGylated interferon plus ribavirin, directacting antiviral, $\mathrm{HCV}$ genotype 1, HCV/HIV co-infection

\section{Introduction}

Chronic hepatitis $\mathrm{C}$ is an important cause of liver-related morbidity and mortality worldwide, ${ }^{1}$ and an estimated 2-3 million people are chronically infected with both hepatitis $\mathrm{C}$ virus (HCV) and human immunodeficiency virus (HIV). ${ }^{2-4}$ Patients who are coinfected with HCV/HIV have higher baseline HCV viral loads, more rapid progression of liver disease, ${ }^{5}$ and higher rates of liver cirrhosis, hepatocellular carcinoma, and hepatic decompensation than patients monoinfected with HCV do. ${ }^{6}$ Although antiretroviral therapy (ART) significantly decreases HIV-associated morbidity, patients coinfected 
with HCV/HIV have higher rates of hepatic decompensation and liver failure than $\mathrm{HCV}$-monoinfected patients. ${ }^{6}$

Hepatitis $\mathrm{C}$ genotype 1 is endemic in Asia (prevalence varies between $15 \%$ and $70 \%$ among all hepatitis $\mathrm{C}$ virus infections). ${ }^{7}$ Sustained virologic response (SVR) rate of peginterferon alfa plus ribavirin (PegIFN/RBV) was around $30-70 \%$ in patients with chronic genotype $1 \mathrm{HCV}$ and HIV coinfection (HCV/HIV) ${ }^{7-10}$ In Taiwan, the prevalence rate of genotype 1 is around $45 \%,{ }^{11}$ and SVR rate of PegIFN/RBV for 48 weeks was $68 \%{ }^{12}$ Direct-acting antivirals (DAAs) have revolutionized the treatment of HCV infection. High SVR rates $(>90 \%)$ were reported with the combination of ombitasvir, dasabuvir, paritaprevir/ritonavir, and ribavirin (TURQUISE1) ${ }^{13}$ daclatasvir plus sofosbuvir (ALLY-2), ${ }^{14,15}$ sofosbuvir/ ledipasvir (ERADICATE, ION-4), ${ }^{16,17}$ grazoprevir/elbasvir (C-WORTHY, C-EDGE CO-INFECTION), ${ }^{18,19}$ and glecaprevir/pibrentasvir (EXPEDITION-2) ${ }^{20}$ in patients coinfected with HCV/HIV. These studies suggest that high rates of SVR are achievable in patients with HCV/HIV.

Grazoprevir/elbasvir was approved by the US Food and Drug Administration in 2016 for the treatment of HCV genotype 1 or 4 infection; however, $\mathrm{HCV}$ resistance testing of the NS5A region in genotype 1a-infected patients before grazoprevir/elbasvir therapy is essential. The guidelines recommend that HCV/HIV coinfected patients must be treated and monitored primarily for drug-drug interactions (DDIs) with ART, and there are less DDIs between grazoprevir (NS3/4A protease inhibitor)/elbasvir (NS5A inhibitor) and ART. ${ }^{21,22}$ Hence, high rate of SVR was achieved and few adverse effects were documented in clinical trials, but reports on PegIFN/RBVexperienced and HCV/HIV co-infected cases in Asia are scarce. Therefore, in the present study, we aimed to evaluate the efficacy and tolerability of grazoprevir/elbasvir in patients with chronic genotype $1 \mathrm{HCV} / \mathrm{HIV}$ co-infection who experienced PegIFN/RBV.

\section{Methods}

This study is a prospective, single-center, and open-label clinical trial (NCT03098121). We performed a systemic screening of HCV antibody in all HIV-infected patients in Taoyuan General Hospital between June 1, 2012 and November 30, 2018 (Figure 1). HCV RNA testing was performed for patients with positive HCV antibody who received treatment with PegIFN/RBV.

Patients who failed PegIFN/RBV treatment were rescreened for HCV RNA and genotype, and patients with HCV RNA $\geq 10,000 \mathrm{IU} / \mathrm{mL}$ and genotype $1 \mathrm{a}$ or $1 \mathrm{~b}$ were enrolled to receive grazoprevir/elbasvir. Written informed consent was obtained from all participants included in the study and the study protocol conforms to the ethical guidelines of the 1975 Declaration of Helsinki as reflected in a priori approval by the Research Ethics Committee or institutional review board of Taoyuan General Hospital.

\section{Study population}

HIV-infected men and non-pregnant women aged $\geq 18$ years with HCV genotype 1 infection, who experienced PegIFN/ RBV treatment, were eligible for grazoprevir/elbasvir treatment. Patients with HCV RNA $>10,000 \mathrm{IU} / \mathrm{mL}$, stable ART with confirmed plasma HIV-1 RNA <200 copies/mL, and CD4 T-cell count $>100$ cells $/ \mu \mathrm{L}$ were enrolled. Patients with compensated cirrhosis were also allowed to be enrolled. The exclusion criteria were as follows: patients with decompensated liver disease (presence or history of ascites, esophageal or gastric variceal bleeding, hepatic encephalopathy, or other signs of advanced liver diseases); liver cirrhosis with ChildPugh class B or C, or with a Child-Turcotte-Pugh score of more than 6 points and albumin below $3 \mathrm{~g} / \mathrm{dL}$ or platelet count below $75,000 / \mu \mathrm{L}$; and hepatitis B virus coinfection.

\section{Study procedures}

This is a single arm and open-label clinical trial. All patients were prescribed grazoprevir/elbasvir with or without ribavirin, and the laboratory tests were performed at Taoyuan general hospital. Samples were assessed for HCV RNA at baseline, weeks 4, 12, and 16 (only for patients with genotype 1a) of treatment, and at follow-up week 12. Plasma HCV RNA viral loads were measured at Taoyuan General Hospital, Ministry of Health and Welfare, Taoyuan City, using Roche LightCycler RNA Master SYBR Green I/High Pure Viral Nucleic Acid Kit with a lower limit of quantitation of less than $10 \mathrm{IU} / \mathrm{mL}$. HCV genotype was determined using Abbott HCV Real Time Genotype II assay (Abbott Diagnostics, Chicago, IL, USA). HIV RNA was measured with COBAS AmpliPrep/COBAS TaqMan HIV-1 test version 2.0 (Roche), with a lower limit of quantitation of less than 20 copies $/ \mathrm{mL}$. The method to detect RASs was Sanger sequencing, and emergent resistance variant testing was performed in patients with genotype 1a who experienced virologic failure. The written report only included the presence or absence of resistance-associated substitutions (RASs) in NS5A gene: $\mathrm{M} / \mathrm{L} 28 \mathrm{~T} / \mathrm{A}, \mathrm{Q} / \mathrm{R} 30 \mathrm{E} / \mathrm{H} / \mathrm{R} / \mathrm{G} / \mathrm{K} / \mathrm{L} / \mathrm{D}, \mathrm{L} 31 \mathrm{M} / \mathrm{V} / \mathrm{F}, \mathrm{H} 58 \mathrm{D}$, or $\mathrm{Y} 93 \mathrm{C} / \mathrm{H} / \mathrm{N}$.

The Fibrosis-4 (FIB-4) score is a non-invasive scoring system based on several laboratory tests that helps to estimate 


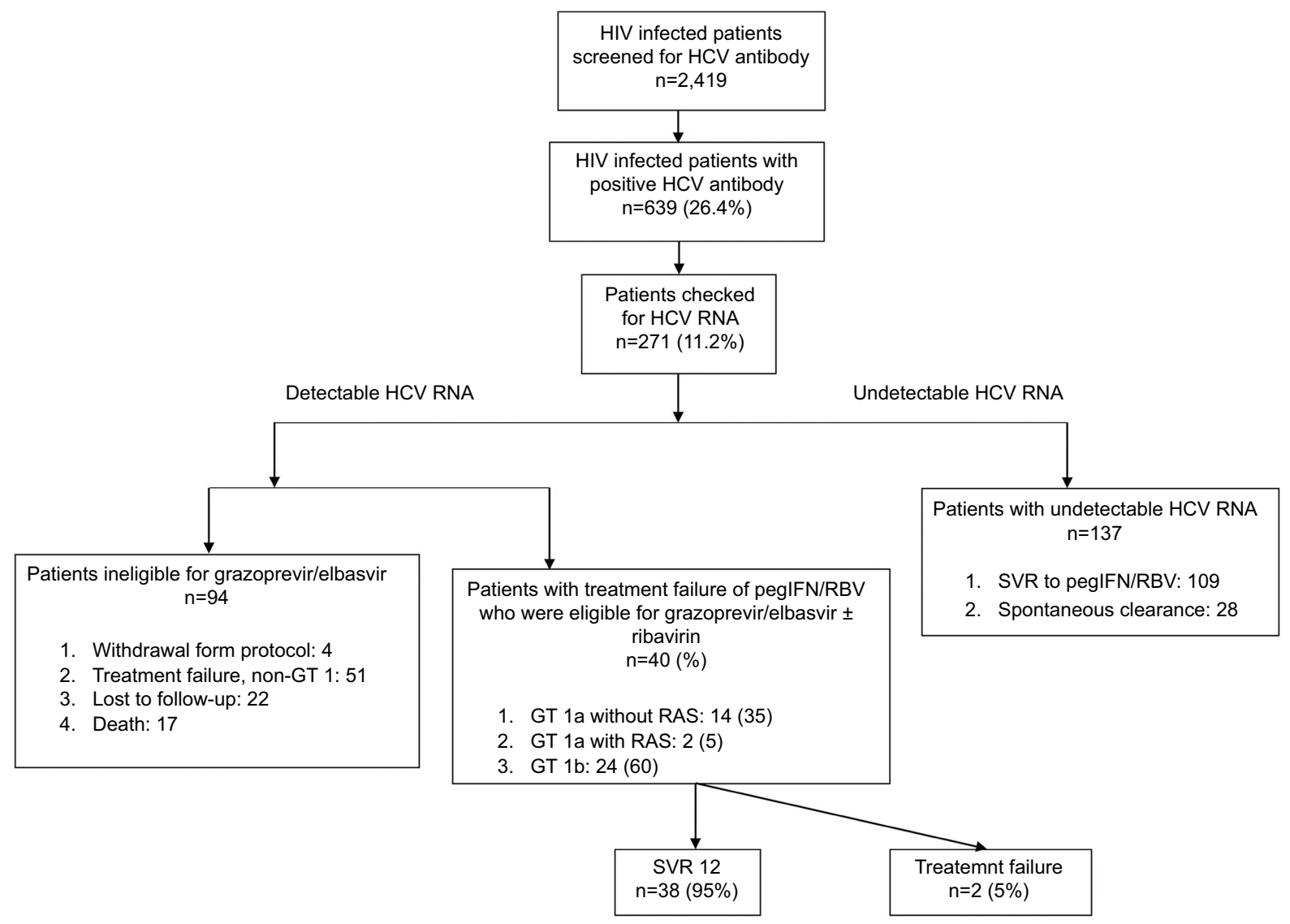

Figure I Flowchart of enrollment of patients with chronic genotype I HCV and HIV co-infection who failed peginterferon alfa plus ribavirin treatment. Abbreviations: HCV, hepatitis C virus; GT, genetype; pegIFN/RBV, peginterferon alfa plus ribavirin; SVR, sustained virologic response.

the amount of scarring in the liver. ${ }^{23,24}$ This score was assessed in liver disease due to hepatitis $\mathrm{C}$ and nonalcoholic steatohepatitis, and the fibrosis status of patients was presented with FIB-4 score in our study. Tolerability was assessed through monitoring of adverse events, vital signs, and laboratory parameters. The events of clinical interest were first instance of alanine aminotransferase (ALT) or aspartate aminotransferase (AST) more than three times the upper limit of normal values and more than $100 \mathrm{U} / \mathrm{L}$. Samples were taken from all patients at baseline and at the time of failure in patients who met the virologic failure criteria (HCV RNA concentration more than the lower limit of quantitation measured from two separate blood draws within 2 weeks).

\section{Study treatment}

Patients with chronic genotype 1a, with or without RASs in NS5A gene, received grazoprevir $100 \mathrm{mg}$ and elbasvir $50 \mathrm{mg}$ in a fixed-dose combination tablet once daily with ribavirin for 16 weeks. Patients with chronic genotype $1 \mathrm{~b}$ received grazoprevir $100 \mathrm{mg}$ and elbasvir $50 \mathrm{mg}$ in a fixed-dose combination tablet once daily for 12 weeks.

\section{Statistical analysis}

Efficacy and safety analyses were performed using data from the per-protocol population, which was defined as all patients who completed the study drug treatment. The number and percentage of patients achieving efficacy endpoints of sustained virologic response at 12 weeks (SVR 12) were summarized, and the corresponding 95\% confidence intervals (CIs) were calculated. Adverse events and laboratory values were summarized for each treatment group (Table 3). The statistical significance of the difference between groups was determined using $\chi^{2}$ tests for categorical variables and using Student's $t$-tests for two independent means for quantitative variables. The cutoff for statistical significance was set at $p \leq 0.05$. The statistical analyses were performed with SPSS 19.0 software (SPSS Inc., Chicago, IL, USA). 


\section{Results}

\section{Grazoprevir/elbasvir treatment}

Overall, 2,419 HIV-infected patients were screened for HCV antibody during a clinical visit from June 1, 2012. Among them, 639 patients (26.4\%) were found to have positive HCV antibody. Of these 639 patients, 271 patients $(11.2 \%)$ were tested for HCV RNA (Figure 1). One hundred and thirty-seven patients had undetectable HCV RNA, of whom, 109 patients had SVR due to PegIFN/RBV treatment and 28 patients had spontaneous clearance. Among 134 patients with detectable HCV RNA, 94 patients were ineligible for grazoprevir/elbasvir treatment. Among these 94 patients, 51 patients who experienced treatment failure with PegIFN/RBV were non-genotype 1, 22 patients lost to follow-up, and 17 patients died. Forty patients were eligible for grazoprevir/elbasvir treatment, of whom, 14 patients (35\%) had genotype 1a without RAS, 2 patients (5\%) had genotype 1a with RASs, and 24 patients $(60 \%)$ had genotype $1 \mathrm{~b}$ (Figure 1).

\section{Patient characteristics}

The first patient started treatment on July 24, 2017, and the last patient completed 12 weeks of follow-up on November 8,2018 . The baseline characteristics are presented in Table 1. Most of the patients were men (92.5\%) and intravenous drug users (92.5\%). The median patient age was 42 years, and the median CD4 cell count was 504 cells $/ \mu$ L. Thirty-six patients $(90 \%)$ had HIV RNA $<50$ copies/mL. Twenty-two patients $(55 \%)$ received emtricitabine and tenofovir disoproxil fumarate, and 17 patients $(42.5 \%)$ received lamivudine and abacavir as ART, along with rilpivirine $(\mathrm{n}=20,50 \%)$, dolutegravir $(\mathrm{n}=17,42.5 \%)$, or raltegravir $(\mathrm{n}=2,5 \%)$. Twenty-eight patients $(70 \%)$ experienced relapse or re-infection from previous PegIFN/RBV, and 12 patients (30\%) withheld treatment due to toxicity of PegIFN/RBV. Overall, 31 patients (77.5\%) had HCV RNA levels $>800000 \mathrm{IU} / \mathrm{mL}$ and 5 patients $(12.5 \%)$ had FIB-4 score $>3.25$.

\section{Treatment outcome}

Overall, SVR 12 was achieved in 38 of 40 patients (95\%) (Figure 1). Two patients relapsed after having undetectable HCV RNA concentrations at the end of treatment. The relapsed patients were non-cirrhotic and included one patient with HCV genotype 1a infection and one patient with $\mathrm{HCV}$ genotype $1 \mathrm{~b}$ infection at enrollment.
Table I Baseline characteristics of patients with chronic genotype I HCV and HIV co-infection who failed peginterferon alfa plus ribavirin treatment

\begin{tabular}{|c|c|}
\hline Characteristics & $\begin{array}{l}\text { Patient number } \\
(n=40)\end{array}$ \\
\hline $\begin{array}{l}\text { Age, y/o, median (IQR) } \\
\text { Male, n (\%) }\end{array}$ & $\begin{array}{l}42(4 \mid-47) \\
37(92.5)\end{array}$ \\
\hline $\begin{array}{l}\text { Mode of HIV acquisition } \\
\text { PWID, n (\%) } \\
\text { MSM, n (\%) } \\
\text { Heterosexual, n (\%) }\end{array}$ & $\begin{array}{l}37(92.5) \\
2(5) \\
I(2.5)\end{array}$ \\
\hline 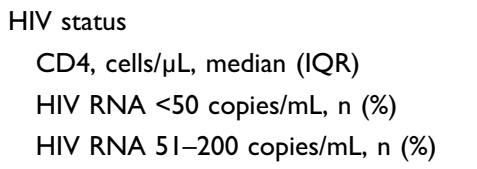 & $\begin{array}{l}504(32 \mid-689) \\
36(90) \\
4(10)\end{array}$ \\
\hline $\begin{array}{l}\text { HAART regimens } \\
\text { ABC/3TC/DTG (Triumeq), n (\%) } \\
\text { TDF/FTC/RPV (Complera), n (\%) } \\
\text { Truvada + DTG or RAL, n (\%) } \\
\text { Kivexa + RAL, n (\%) }\end{array}$ & $\begin{array}{l}16(40) \\
20(50) \\
2(5) \\
1(2.5)\end{array}$ \\
\hline $\begin{array}{l}\text { HCV genotype } \\
\text { GT Ia, n (\%) } \\
\text { GT Ib, n (\%) } \\
\text { GT I a with baseline RASs }\end{array}$ & $\begin{array}{l}16(40) \\
24(60) \\
2(5)\end{array}$ \\
\hline $\begin{array}{l}\text { Relapse or re-infection from previous } \\
\text { PegIFN/RBV, } n(\%) \\
\text { Treatment failure due to AEs of PegIFN/ } \\
\text { RBV, } n(\%)\end{array}$ & $\begin{array}{l}28(70) \\
12(30)\end{array}$ \\
\hline $\begin{array}{l}\text { HCV RNA at baseline, log I0, median } \\
\text { (IQR), IU/mL } \\
\quad<800,000 \mathrm{IU} / \mathrm{mL}, \mathrm{n}(\%) \\
>800,000 \mathrm{IU} / \mathrm{mL}, \mathrm{n}(\%)\end{array}$ & $\begin{array}{l}6.3(3.98-7.12) \\
9(22.5) \\
31(77.5)\end{array}$ \\
\hline $\begin{array}{l}\text { Fibrosis-4 score, } \mathrm{n}(\%) \\
\quad<1.45 \\
\quad 1.45-3.25 \\
>3.25\end{array}$ & $\begin{array}{l}23(57.5) \\
12(30.0) \\
5(12.5)\end{array}$ \\
\hline $\begin{array}{l}\text { AST, median (IQR), U/L } \\
\text { ALT, median (IQR), U/L } \\
\text { Platelets, median (IQR), Giga/L }\end{array}$ & $\begin{array}{l}35(27-45) \\
35(29-72) \\
178.5(157-23 \mid)\end{array}$ \\
\hline
\end{tabular}

Abbreviations: PWID, people who inject drugs; MSM, men who have sex with men; ABC, abacavir; 3TC, lamivudine; DTG, dolutegravir; TDF, tenofovir; FTC, emtricitabine; RPV, rilpivirine; RAL, raltegravir; GT, genotype; RASs, resistanceassociated substitutions; PegIFN/RBV, Peginterferon alfa and ribavirin; ALT, alanine aminotransferase; AST, aspartate aminotransferase.

The first patient who did not achieve SVR12 was detected with a different HCV genotype during followup (genotype 1a at enrollment; genotype 6 at follow-up 
Table 2 Rates of sustained virologic response after 12 weeks of follow-up

\begin{tabular}{|l|l|l|l|l|}
\hline \multirow{2}{*}{ Outcome } & All patients $(\mathbf{n = 4 0 )}$ & \multicolumn{2}{|l|}{ Genotype Ia } & \multirow{2}{*}{ Genotype Ib (n=24) } \\
\cline { 3 - 5 } & & Without RASs (n= 14) & With RASs (n=2)* & \\
\hline SVR I2, n (\%) & $38(95)$ & $13(92.9)$ & $2(100)$ & $23(95.8)$ \\
Failure, n (\%) & $2(5)$ & $\mathrm{I}(7.1)$ & $0(0)$ & $\mathrm{I}(4.2)$ \\
\hline
\end{tabular}

Note: *The following RASs were detected in two patients: $M 28(n=2)$ and $L 3 \mid(n=I)$.

Abbreviations: RASs, resistance-associated substitutions; SVR 12, sustained virologic response at 12 week.

Table 3 Safety and adverse events in treatment period and first 12 weeks of follow-up

\begin{tabular}{|c|c|c|c|}
\hline Adverse events & $\begin{array}{l}\text { Patients with genotype Ia } \\
(n=16)\end{array}$ & $\begin{array}{l}\text { Patients with genotype Ib } \\
(n=24)\end{array}$ & $\begin{array}{l}\text { Total patients } \\
(n=40)\end{array}$ \\
\hline All adverse events, $n$ & 31 & 26 & 57 \\
\hline Serious adverse events, $n$ & 2 & 0 & 2 \\
\hline Serious drug-related adverse events, $\mathrm{n}$ & 0 & 0 & 0 \\
\hline Discontinuation due to adverse events, $n$ & 0 & 0 & 0 \\
\hline Deaths, $n$ & 0 & 0 & 0 \\
\hline All clinical adverse events, $n$ & 29 & 26 & 55 \\
\hline \multicolumn{4}{|l|}{$\begin{array}{l}\text { The numbers of common clinical adverse } \\
\text { events, } n(\%)\end{array}$} \\
\hline Fatigue & $6(37.5)$ & $5(20.8)$ & II (27.5) \\
\hline Irritable mood & $3(18.8)$ & $0(0)$ & $3(7.5)$ \\
\hline Depression & $2(12.5)$ & $4(16.7)$ & $6(15)$ \\
\hline Headache & $3(18.8)$ & $0(0)$ & $3(7.5)$ \\
\hline Nausea or vomiting & $3(18.8)$ & $3(12.5)$ & $6(15)$ \\
\hline Pruritus & $3(18.8)$ & $0(0)$ & $3(7.5)$ \\
\hline Insomnia & $2(12.5)$ & I (4.2) & $3(7.5)$ \\
\hline \multicolumn{4}{|l|}{ Laboratory adverse events, n (\%) } \\
\hline ALT, Grade $3(>5 \times$ ULN) & 0 & 0 & 0 \\
\hline AST, Grade $3(>5 \times$ ULN) & 0 & 0 & 0 \\
\hline Total bilirubin, Grade $3(>3 \times$ ULN) & 0 & 0 & 0 \\
\hline Decrease in platelet, Grade 3 & 0 & 0 & 0 \\
\hline Decrease in hemoglobin, Grade 3 & $2(12.6)$ & 0 & $2(5)$ \\
\hline RBV dose reduction due to toxicity & $2(12.6)$ & 0 & $2(5)$ \\
\hline
\end{tabular}

Abbreviations: ULN, upper limit of normal; RBV, ribavirin.

week 12). In the analysis, first patient was classified as relapsed, but sequencing data were consistent with reinfection after treatment.

Two of 16 genotype 1a-infected patients (12.5\%) harbored baseline RASs in NS5A gene, and the specific RASs detected in these two patients were Met28Val (M28V; two patients) and Leu31Met (L31M; one patient) (Table 2). In these patients, the presence of NS5A RASs at baseline did not reduce SVR12 rates. The SVR12 rates were $100 \%$ in patients with baseline NS5A RASs (Table 2).

\section{Safety and tolerability}

Of 20 patients with FIB- $4>1.45$ at baseline, the median FIB-4 was 2.9. The FIB-4 score was 1.6 at week $4(p=0.025), 0.8$ at end of treatment (EOT), and 0.71 at SVR12 (Figure 2). Overall, two serious adverse events and 57 adverse events occurred. These two serious adverse events were classified as ribavirin-related anemia (Grade 3). Among possible drugrelated clinical adverse events, the most common events were fatigue $(n=11 ; 27.5 \%)$, depression $(n=6 ; 15 \%)$, and nausea or vomiting ( $\mathrm{n}=6 ; 15 \%)$ (Table 3 ). Among laboratory adverse events, there were two (5\%) Grade 3 adverse events. 


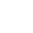

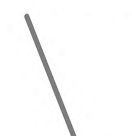

\section{(1)}

.

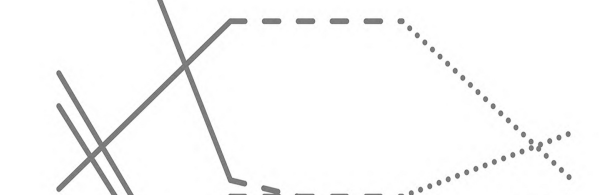

$$
0.0
$$

\section{Baseline Week $4 \quad$ EOT $\quad$ SVR 12}

Figure 2 Improvement of fibrosis-4 score after treatment of grazoprevir and elbasvir with or without ribavirin.

Abbreviations: EOT, end of treatment; SVR 12, sustained virologic response at 12 week.

We noted no late elevations in ALT or AST levels. There was no discontinuation of the study drug in the whole study population. Among the 16 patients who received ribavirin, two cases of drug-related anemia occurred, following which ribavirin dose was reduced to $50 \%$.

\section{Discussion}

In this non-randomized, open-label clinical trial, we aimed to evaluate the efficacy and tolerability of grazoprevir/elbasvir in patients with chronic genotype $1 \mathrm{HCV}$ and HIV coinfection who experienced PegIFN/RBV. We found that once-daily administration of grazoprevir/elbasvir for 12-16 weeks, with or without ribavirin, had a very high SVR12 rate of $95 \%$ and showed an excellent safety profile in patients with chronic genotype $1 \mathrm{HCV}$ and HIV co-infection who failed PegIFN/RBV.

HCV treatment should be a priority for patients with HCV/HIV co-infection. ${ }^{21}$ Efficacy and adverse event rates of HCV DAAs in patients with HCV/HIV co-infection were similar to those observed in patients with HCV alone. ${ }^{14,16,19,20}$
HIV/HCV co-infected patients are not considered a special population anymore, although there are certain barriers to DAA therapy in these patients. High rates of $\mathrm{HCV}$ relapse or re-infection are observed, and dedicated care is required in the management of $\mathrm{HIV} / \mathrm{HCV}$ co-infected patients with special social and behavioral issues or drug-drug interactions, especially people who inject drugs (PWID). ${ }^{25}$ In our study, majority of the patients belonged to PWID category $(n=37$, $92.5 \%)$, and SVR12 rate of $94.6 \%(n=35)$ was achieved. Grazoprevir/elbasvir plus ribavirin was administered for 16 weeks in all PegIFN/RBV failure patients with chronic genotype 1a with or without RASs in our study, and no relapse was identified. Only two patients failed to achieve SVR12, but they showed good adherence to grazoprevir/elbasvir throughout the study. One patient had an HCV viral load of $5.5 \mathrm{log}$ RNA (292,288 IU/mL and genotype 1a at enrollment), and he achieved undetectable viral loads $(<10 \mathrm{IU} / \mathrm{mL})$ at week 4 and week 16 (end of treatment); however, genotype 6 with an $\mathrm{HCV}$ viral load of $2.6 \log$ RNA (377 IU/mL) was detected at week 28 (at follow-up week 12). It was hard to distinguish between re-infection and mixed infection et enrollment for this patient, because HCV RNA was only $377 \mathrm{IU} / \mathrm{mL}$. Although our method (Roche LightCycler RNA Master SYBR Green I/High Pure Viral Nucleic Acid Kit) could detect HCV RNA with a lower limit of quantitation of less than 10 $\mathrm{IU} / \mathrm{mL}$, only one dominant strain can be identified; however, the prevalence of mixed infection among PWID ranges from $14 \%$ to $39 \%{ }^{26}$ In Taiwan, the prevalence rate of genotype 6 was around $28.0 \%$ among PWID with chronic HCV/HIV infection. ${ }^{11}$ Hence, next-generation sequencing may be more suitable to identify mixed infection of HCV before treatment in this population. ${ }^{27}$ The other patient had an HCV viral load of $4.8 \log$ RNA $(68,966 \mathrm{IU} / \mathrm{mL}$ and genotype $1 \mathrm{~b}$ at enrollment), and he achieved undetectable viral loads $(<10 \mathrm{IU} / \mathrm{mL})$ at week 4 and week 12 (end of treatment); however, genotype 1b with $3.9 \log$ RNA $(2,202 \mathrm{IU} / \mathrm{mL})$ was detectable at week 24 (at follow-up week 12). In most clinical trials and realworld data demonstrating high SVR12 in genotype $1 \mathrm{~b}$ infection, ${ }^{16-20,28}$ most of the treatment failures were identified as re-infection or lost to follow-up. Therefore, we could not exclude the possibility of re-infection in the second patient with genotype $1 \mathrm{~b}$ at follow-up week 12 . In our study, dolutegravir, rilpivirine, or raltegravir in combination with a nucleoside or nucleotide reverse transcriptase inhibitor was prescribed as concurrent ART. No association was observed between relapse and ART regimen, suggesting that plasma concentrations of grazoprevir/elbasvir were not affected by ART. 
Overall, grazoprevir/elbasvir-based treatment was safe. More adverse events were observed in patients treated with ribavirin than that in patients treated without ribavirin. Serious adverse events (anemia caused by ribavirin) occurred in only two patients (5\%), but treatment discontinuation was not reported. These data are similar to those reported in other studies. ${ }^{16-20,29}$

Most of the patients were PWID in our study (92.5\%), and $87.5 \%$ of them revealed a FIB- 4 score of $<3.25$. In Taiwan, until December 2018, treatment with the newest HCV DAAs was restricted to patients with a FIB-4 score of $>3.25$, owing to the high cost of these drugs. Hence, for majority of coinfected patients in Taiwan, DAA treatment was not covered by national health insurance by December 2018. This study offered HCV treatment with grazoprevir-elbasvir to patients with chronic genotype 1 HCV/HIV co-infection who experienced PegIFN/RBV, regardless of their fibrosis stage. By providing HCV treatment access to high-risk population or all $\mathrm{HCV}$-infected patients, we were able to reduce transmission of HCV to other PWID or their sexual partners, as well as the deterioration of liver-associated morbidities or mortalities. ${ }^{30}$ Fortunately, the Bureau of National Health Insurance launched DAA therapy for all $\mathrm{HCV}$-infected patients in Taiwan since January 2019.

There are several limitations to our study. First, it was designed in an era when open-label single-arm studies with a historical control were acceptable for the assessment of DAA agents. This study design is consistent with other recent non-randomized phase 3 studies. ${ }^{7,10}$ Second, although there is no comparator, it is important to note the difference from the C-EDGE CO-INFECTION study, ${ }^{19}$ because patients with chronic genotype $1 \mathrm{HCV} / \mathrm{HIV}$ coinfection who experienced PegIFN/RBV were enrolled in our study, and efficacy was similar. Third, the sample size might be too small to support primary efficacy analysis, and all patients were enrolled in one study site; hence, the outcome cannot be extrapolated to patients from other clinical settings, such as China. Fourth, the population sequencing method also has one limitation. Although it can be used in samples from patients with a viral load of more than $20 \mathrm{IU} / \mathrm{mL}$, it is not capable of detecting variants that represent less than $25 \%$ of the total viral population.

In conclusion, our study showed that once-daily grazoprevir/elbasvir with or without ribavirin for 12 or 16 weeks is effective for genotype 1 patients co-infected with HIV with or without cirrhosis who experienced PegIFN/ RBV, including the important subpopulation of people who inject drugs (PWID). These data are consistent with those of previous trials using this regimen in the monoinfected population.

\section{Data sharing statement on clinical trial data}

Our authors will share individual participant data collected during the trial after de-identification, including study protocol and analysis plan. Data should be directed to s841060@gm. ym.edu.tw. To gain access, data requestors will need to sign a data access agreement, and data will be made available immediately after publication. No end date.

\section{Abbreviations list}

PWID, people who inject drugs; MSM, men who have sex with men; ABC, abacavir; 3TC, lamivudine; DTG, dolutegravir; TDF, tenofovir; FTC, emtricitabine; RPV, rilpivirine; RAL, raltegravir; GT, genotype; RASs, resistanceassociated substitutions; ALT, alanine aminotransferase; AST, aspartate aminotransferase; PegIFN/RBV, peginterferon alfa plus ribavirin; HCV/HIV, hepatitis $\mathrm{C}$ virus and human immunodeficiency virus; ART, antiretroviral therapy.

\section{Acknowledgments}

We would like to thank the patients for participation in this study. We would also like to thank Merck for provision of labeled study drugs. Financial support was provided for the conduct of the research by Taoyuan General Hospital, Ministry of Health and Welfare, Taoyuan City, Taiwan, and study medications were provided by Merck.

\section{Author contributions}

YCL, SWL, and CYC wrote the manuscript; SYC, YCL, and $\mathrm{CYC}$ conducted the experiments; SYK, HTH, SYC, WWW, NLS, and SHC helped to recruit study subjects and provide clinical suggestions; CYC and SWL helped to collect the clinical specimens and datasheet. All authors contributed to data analysis, drafting and revising the article, gave final approval of the version to be published, and agree to be accountable for all aspects of the work.

\section{Disclosure}

The authors report no conflicts of interest in this work. 


\section{References}

1. Lavanchy D. The global burden of hepatitis C. Liver Int. 2009;29 (Suppl 1):74-81. doi:10.1111/j.1478-3231.2008.01934.x

2. Alter MJ. Epidemiology of viral hepatitis and HIV co-infection. J Hepatol. 2006;44(Suppl 1):S6-9. doi:10.1016/j.jhep.2005.09.019

3. Peters L, Klein MB. Epidemiology of hepatitis $\mathrm{C}$ virus in HIV-infected patients. Curr Opin HIV AIDS. 2015;10(5):297-302. doi:10.1097/COH.0000000000000181

4. Platt L, Easterbrook P, Gower E, et al. Prevalence and burden of HCV co-infection in people living with HIV: a global systematic review and meta-analysis. Lancet Infect Dis. 2016;16(7):797-808. doi:10.1016/S1473-3099(16)30197-9

5. Rockstroh JK, Peters L, Grint D, et al. Does hepatitis C viremia or genotype predict the risk of mortality in individuals co-infected with HIV? J Hepatol. 2013;59(2):213-220. doi:10.1016/j.jhep.2013.04.005

6. Lo Re V 3rd, Kallan MJ, Tate JP, et al. Hepatic decompensation in antiretroviral-treated patients co-infected with HIV and hepatitis C virus compared with hepatitis C-monoinfected patients: a cohort study. Ann Intern Med. 2014;160(6):369-379.

7. Bunchorntavakul C, Chavalitdhamrong D, Tanwandee T. Hepatitis $\mathrm{C}$ genotype 6: a concise review and response-guided therapy proposal. World J Hepatol. 2013;5(9):496-504. doi:10.4254/wjh.v5.i9.496

8. Laguno M, Cifuentes C, Murillas J, et al. Randomized trial comparing pegylated interferon alpha- $2 \mathrm{~b}$ versus pegylated interferon alpha-2a, both plus ribavirin, to treat chronic hepatitis $\mathrm{C}$ in human immunodeficiency virus patients. Hepatology. 2009;49(1):22-31. doi:10.1002/hep. 22598

9. Chung RT, Andersen J, Volberding P; AIDS Clinical Trials Group A5071 Study Team. Peginterferon alfa-2a plus ribavirin versus interferon alfa-2a plus ribavirin for chronic hepatitis $\mathrm{C}$ in HIV-coinfected persons. $N$ Engl J Med. 2004;351(5):451-459. doi:10.1056/NEJMcp041956

10. Torriani FJ, Rodriguez-Torres M, Rockstroh JK, et al. Peginterferon alfa-2a plus ribavirin for chronic hepatitis $\mathrm{C}$ virus infection in HIV-infected patients. $N$ Engl J Med. 2004;351(5):438-450. doi:10.1056/NEJMcp041956

11. Liu JY, Lin HH, Liu YC, et al. Extremely high prevalence and genetic diversity of hepatitis $\mathrm{C}$ virus infection among HIV-infected injection drug users in Taiwan. Clin Infect Dis. 2008;46 (11):1761-1768. doi:10.1086/587992

12. Liu CH, Sheng WH, Sun HY, et al. Peginterferon plus ribavirin for HIV-infected patients with treatment-naïve acute or chronic HCV infection in Taiwan: a prospective cohort study. Sci Rep. 2015;5:17410. doi:10.1038/srep17410

13. Sulkowski MS, Eron JJ, Wyles D, et al. Ombitasvir, paritaprevir co-dosed with ritonavir, dasabuvir, and ribavirin for hepatitis $\mathrm{C}$ in patients co-infected with HIV-1: a randomized trial. JAMA. 2015;313 (12):1223-1231. doi:10.1001/jama.2015.1328

14. Wyles DL, Ruane PJ, Sulkowski MS, et al. Daclatasvir plus sofosbuvir for HCV in patients coinfected with HIV-1. $N$ Engl $J$ Med. 2015;373(8):714-725. doi:10.1056/NEJMoa1503153

15. Luetkemeyer AF, McDonald C, Ramgopal M, Noviello S, Bhore R, Ackerman P. 12 weeks of daclatasvir in combination with sofosbuvir for HIV-HCV coinfection (ALLY-2 Study): efficacy and safety by HIV combination antiretroviral regimens. Clin Infect Dis. 2016;62 (12):1489-1496. doi:10.1093/cid/ciw163

16. Naggie S, Cooper C, Saag M, et al. Ledipasvir and sofosbuvir for HCV in patients coinfected with HIV-1. N Engl J Med. 2015;373 (8):705-713. doi:10.1056/NEJMoa1501315
17. Osinusi A, Townsend K, Kohli A, et al. Virologic response following combined ledipasvir and sofosbuvir administration in patients with HCV genotype 1 and HIV co-infection. JAMA. 2015;313(12): 1232-1239. doi:10.1001/jama.2015.1373

18. Sulkowski M, Hezode C, Gerstoft J, et al. Efficacy and safety of 8 weeks versus 12 weeks of treatment with grazoprevir (MK-5172) and elbasvir (MK-8742) with or without ribavirin in patients with hepatitis $\mathrm{C}$ virus genotype 1 mono-infection and Hiv/hepatitis $\mathrm{C}$ virus co-infection (C-WORTHY): a randomized, open-label phase 2 trial. Lancet. 2015;385(9973):1087-1097.

19. Rockstroh JK, Nelson M, Katlama C, et al. Efficacy and safety of grazoprevir (MK-5172) and elbasvir (MK-8742) in patients with hepatitis $\mathrm{C}$ virus and HIV co-infection (C-EDGE CO-INFECTION): a non-randomised, open-label trial. Lancet HIV. 2015;2(8):e319-327. doi:10.1016/S2352-3018(15)00108-3

20. Rockstroh JK, Lacombe K, Viani RM, et al. Efficacy and safety of glecaprevir/pibrentasvir in patients coinfected with hepatitis $\mathrm{C}$ virus and human immunodeficiency virus Type 1: the EXPEDITION-2 Study. Clin Infect Dis. 2018;67(7):1010-1017. doi:10.1093/cid/ciy220

21. American Association for the Study of Liver Disease, Infectious Diseases Society of America. HCV guidance: recommendations for testing, managing, and treating hepatitis C virus. 2017. Available from: http://www.hcvguidelines.org. Accessed May, 2018.

22. European Association for the Study of the Liver. EASL recommendations on treatment of hepatitis C 2018. J Hepatol. 2018. doi:10.1016/j.jhep.2018.03.026

23. Kim BK, Kim DY, Park JY, et al. Validation of FIB-4 and comparison with other simple noninvasive indices for predicting liver fibrosis and cirrhosis in hepatitis B virus-infected patients. Liver Int. 2010;30 (4):546-553. doi:10.1111/j.1478-3231.2009.02192.x

24. Shah AG, Lydecker A, Murray K, Tetri BN, Contos MJ, Sanyal AJ. Nash Clinical Research Network. Comparison of noninvasive markers of fibrosis in patients with nonalcoholic fatty liver disease. Clin Gastroenterol Hepatol. 2009;7(10):1104-1112. doi:10.1016/j. cgh.2009.05.033

25. Sulkowsky MS. HCV-HIV co-infected patients: no longer a 'special' population? Liver Int. 2016;36(Suppl 1):43-46. doi:10.1111/liv.13021

26. Cunningham EB, Applegate TL, Lloyd AR, Dore GJ, Grebely J. Mixed HCV infection and reinfection in people who inject drugsimpact on therapy. Nat Rev Gastroenterol Hepatol. 2015;12(4): 218-230. doi:10.1038/nrgastro.2015.36

27. Dirani G, Paesini E, Mascetra E, et al. A novel next generation sequencing assay as an alternative to currently available methods for hepatitis C virus genotyping. J Virol Methods. 2018;251:88-91. doi:10.1016/j.jviromet.2017.09.027

28. Braun DL, Hampel B, Kouyos R, et al. High cure rates with grazoprevir-elbasvir with or without ribavirin guided by genotypic resistance testing among human immunodeficiency virus/hepatitis C virus-coinfected men who have sex with men. Clin Infect Dis. 2019;68(4):569-576. doi:10.1093/cid/ciy547

29. Werner CR, Schwarz JM, Egetemeyr DP, et al. Second-generation direct-acting-antiviral hepatitis $\mathrm{C}$ virus treatment: efficacy, safety, and predictors of SVR12. World J Gastroenterol. 2016;22(35): 8050-8059. doi:10.3748/wjg.v22.i37.8314

30. Dienstag JL, Ghany MG, Morgan TR; HALT-C Trial Group. A prospective study of the rate of progression in compensated, histologically advanced chronic hepatitis C. Hepatology. 2011;54(2): 396-405. doi: $10.1002 /$ hep. 24370 


\section{Publish your work in this journal}

Infection and Drug Resistance is an international, peer-reviewed openaccess journal that focuses on the optimal treatment of infection (bacterial, fungal and viral) and the development and institution of preventive strategies to minimize the development and spread of resistance. The journal is specifically concerned with the epidemiology of antibiotic resistance and the mechanisms of resistance development and diffusion in both hospitals and the community. The manuscript management system is completely online and includes a very quick and fair peerreview system, which is all easy to use. Visit http://www.dovepress.com/ testimonials.php to read real quotes from published authors.

Submit your manuscript here: https://www.dovepress.com/infection-and-drug-resistance-journal 